J. Clin. Chem. Clin. Biochem.

Vol. 28, 1990, pp. 163-168

(C) 1990 Walter de Gruyter \& Co.

Berlin - New York

\title{
Alveolar Cell Pattern and Chemiluminescence Response of Blood Neutrophils and Alveolar Macrophages in Sheep after Endotoxin Injection
}

\author{
By A. Divenger ${ }^{1}$, G. Regel ${ }^{2}$, Beate Ellendorff ${ }^{2}$, Gertraud Schweitzer ${ }^{1}$, Monika Funck $^{1}$, H. Limbrock ${ }^{2}$, \\ J. A. Sturm ${ }^{2}$ and H. Tscherne ${ }^{2}$
}

Abteilung für Klinische Biochemie ${ }^{1}$ und Unfallchirurgische Klinik ${ }^{2}$ der Medizinischen Hochschule Hannover

(Received April 17/August 25/November 16, 1989)

\begin{abstract}
Summary: In order to study the pathomechanisms of the Adult Respiratory Distress Syndrome in an acute animal model, we monitored the alveolar cell pattern and the stimulatory chemiluminescence responses of blood neutrophils and alveolar macrophages in sheep after Escherichia coli endotoxin injection $(2 \mu \mathrm{g} / \mathrm{kg}$ of body weight). Using appropriate bronchoalveolar lavage techniques, thereby avoiding local inflammation, it was demonstrated that endotoxin injection did not cause any recruitement of neutrophils into the alveoli for a period of up to 24 hours. Following endotoxin injection, blood neutrophils showed a maximal stimulatory response after 5 minutes, and alveolar macrophages after 4 hours. It is concluded that if neutrophils are responsible for initiating the increase in microvascular permeability, then this action must be purely intravascular.
\end{abstract}

\section{Introduction}

In the study of adult respiratory distress syndrome pathomechanisms in experimental animals, the endotoxin-induced clinical and biochemical alterations of the capillo-alveolar section of the lung have been widely investigated in sheep. The application of sublethal doses of $E$. coli endotoxin induces massive and rapid leukopenia $(1,2)$ as well as a reproducible biphasic reaction in the lung microvasculature (3). The early phase is characterized by acute severe pulmonary hypertension, reaching a maximum in 30 to 60 minutes. This is followed later by a phase of increased lung vascular permeability to proteins between 2 and 6 hours after endotoxin injection $(3,4$, 20). Most of the progress in this field has been made with the aid of the sheep lung lymph fistula model, as originally described by Staub (5). In this model, an increased flow of protein-rich lymph in the absence of major haemodynamic changes, and the persistence of a normal or elevated lymph to plasma protein concentration ratio is considered to represent increased vascular permeability. This can be correlated with the effects of substances capable of initiating or preventing lung injury (3). Polymorphonuclear leukocytes and inflammatory mediators liberated by their respiratory burst reactions are considered to be responsible for acute lung injury. This is indicated by neutropenia of the blood, neutrophil accumulation in the lung and an extracellular increase of the granulocytic lysosome content in plasma and bronchoalveolar lavage fluid, which occur before the clinical manifestations of the adult respiratory distress syndrome $(1,3,6-19)$. Hitherto, it has been unclear whether neutrophils damage the capillary-interstitialalveolar structures before and/or during and/or after passage through the blood/air barrier.

Furthermore, it is unclear how or even whether alveolar macrophages are involved. In previous studies we described the endotoxin-induced haemodynamic and biochemical alterations of this sheep model after $2 \mu \mathrm{g} / \mathrm{kg}$ endotoxin bolus injection $(1,20)$. Therefore, we did not reevaluate these parameters in the present study. 
To answer some of these questions, different techniques were employed, using the sheep model, to obtain bronchoalveolar lavage fluid with and without $E$. coli endotoxin bolus injection. Total lavage cell counts were determined and the cell pattern was elucidated from cytocentrifuge smears at various times after the administration of endotoxin. As an index of the metabolic capacity of the cells to produce reactive oxygen-derived agents, the luminol-enhanced chemiluminescence response of blood neutrophils and alveolar macrophages was determined after zymosan $\mathrm{A}$ stimulation.

\section{Materials and Methods}

\section{Animals}

A total of 22 female merino sheep weighing $26-47 \mathrm{~kg}$ each $(\overline{\mathrm{x}}=34.8 \mathrm{~kg})$ were used in this study. All the animals were monitored for several days before the experiment began to ascertain that they were healthy, afebrile, and without any signs of infection (normal white blood cell count; normal chemiluminescence responses of blood and isolated neutrophils). They were anaesthetized with $20 \mathrm{mg}$ sodium pentobarbital per $\mathrm{kg}$ body weight. Polyvinyl arterial and venous catheters were introduced via a femoral incision, and a Swan-Ganz thermodilution catheter (Edwards Model 93A-131-9F) via the right jugular vein. The animals were allowed to recover for 24 hours, then studied for $24 \mathrm{~h}$ in an unanaesthetized and unrestrained state. Within two hours before the start of the experiment, the following parameters were measured to determine base-line values: aortic, pulmonary arterial, pulmonary arterial wedge and central venous pressure, and cardiac output using the thermodilution method.

Venous blood and bronchoalveolar lavage samples were obtained 2 hours before (baseline values $0 \mathrm{~min}$ ) and at varying times after intravenous bolus injection of $E$. coli endotoxin (serotype 055: B5, Sigma Chemicals) $(2 \mu \mathrm{g} / \mathrm{kg}$ of body weight). Control sheep were injected with physiological saline.

\section{Bronchoalveolar lavage techniques}

Two different techniques for obtaining bronchoalveolar lavage fluid were used:

Technique 1 (multiple lavage procedures with a 'fixed position' balloon-tipped catheter): 24 hours before the start of the experiment a Swan-Ganz catheter was installed percutaneously via the subglottic trachea, then fixed in position. After wedging the balloon into a fourth order bronchial segment of the right upper lobe, $20 \mathrm{ml}$ of physiological saline solution were injected through the catheter. The lavage solution was removed by suction after 3 breaths. Recovery of the injected fluid averaged $50 \%$, regardless of whether endotoxin had been injected or not.

Technique 2 (multiple bronchoscopies and multiple lavage procedures): This technique was analogous to that performed on humans (21). After anaesthesia, the bronchoscope (Fujinon BRO-YL with light source Fujinon FIL-150, Fuji Photo Optical-Europe-GmbH, Düsseldorf, F. R.G.) was installed in a fourth order bronchial segment in wedge position. For multiple consecutive lavage fluid samplings from a single animal, a repetitive use of the same segment of the right upper lobe (s) as well as aspirates from different segments (d) of the right and the left upper lobe, distant from the s-segment, were lavaged. This method prevented contamination of the lavage sample by fluid from neighboring bronchioli and by products of local inflammatory reactions due to preceding aspirations. Injected physiological saline $(20 \mathrm{ml})$ was recovered with a mean value of $60 \%$.

\section{Anaesthesia}

Two different methods of anaesthetization were used.

Short-term anaesthesia. This procedure was carried out using pentobarbital (Nembutal ${ }^{\circledR}$, CEVA GmbH, Bad Segeberg, F. R. G.), $25 \mathrm{mg} / \mathrm{kg}$ of body weight, and it was repeated before each lavage procedure.

Long-term anaesthesia: This procedure was carried out by inhalation narcosis (halothane $/ \mathrm{N}_{2} \mathrm{O}$ ) using the ventilator Romulus 19 (Dräger, Lübeck, F. R. G.).

\section{Processing of bronchoalveolar lavage fluid}

After the volume had been ascertained, the lavage fluid was centrifuged at $600 \mathrm{~g}$ and $20^{\circ} \mathrm{C}$ for $10 \mathrm{~min}$ and the cell pellet was resuspended in $500 \mu \mathrm{l}$ of Minimal Essential Medium Dulbecco for chemiluminescence (Boehringer-Mannheim, F. R. G.). Neutrophil and macrophage counts were obtained by staining with Türk's solution (acetic acid gentian violet solution, E. Merck, Darmstadt, F. R. G.) and Tucker's solution (22), using a Neubauer haemocytometer and a Universal Microscope (Zeiss, Oberkochen, F.R.G.), magnification $\times 250$. The cell suspension was then diluted with Minimal Essential Medium to give a cell count of $5 \cdot 10^{8} / 1$, and a $50 \mu \mathrm{l}$ aliquot was used for the chemiluminescence measurement. Another aliquot of the concentrated suspension was used to prepare cytocentrifuge smears (Cytospin II, Shandon, Frankfurt, F. R. G.). After Pappenheim staining, the distribution of macrophages, neutrophils and lymphocytes was determined using the Universal Microscope and immersion oil, magnification $\times 1600$.

\section{Granulocyte isolation from blood}

Neutrophils were isolated from citrated venous blood (1 vol of $3.13 \%$ citrate solution, Fresenius, Bad Homburg, F. R. G., +9 vol of blood). The blood was diluted $1: 2$ with physiological saline, and $2 \mathrm{ml}$ were placed on $4 \mathrm{ml}$ of a Percoll solution (Pharmacia, Uppsala, Sweden), volume fraction 0.5. After centrifugation at $350 \mathrm{~g}$ and $20^{\circ} \mathrm{C}$ for $25 \mathrm{~min}$, the upper layer (monocytes, platelets, lymphocytes, plasma) was aspirated and discarded. The lower layer (red blood cells, granulocytes) was resuspended in $8 \mathrm{ml}$ of phosphate-buffered saline (BoehringerMannheim, F. R.G.), centrifuged at $600 \mathrm{~g}$ and $20^{\circ} \mathrm{C}$ for $5 \mathrm{~min}$, and the supernatant discarded. The cell pellet was treated with $2 \mathrm{ml}$ of ice cold water (lysis of red blood cells). After $30 \mathrm{~s}, 1 \mathrm{ml}$ of $2.7 \%$ sodium chloride solution and $9 \mathrm{ml}$ of phosphate-buffered saline were added. After centrifugation at $600 \mathrm{~g}$ and $20^{\circ} \mathrm{C}$ for $5 \mathrm{~min}$, the supernatant was discarded, the granulocyte pellet was again washed with $12 \mathrm{ml}$ of phosphate-buffered saline, then resuspended in $500 \mu \mathrm{l}$ of Minimal Essential Medium. An aliquot was used for cell counting in a Neubauer haemocytometer after staining with Türk's solution, and the cell suspension was diluted to give a cell count of $5 \cdot 10^{8} / 1$ Minimal Essential Medium. The purity of the isolated neutrophils was $>98 \%$ for control animals and $>96 \%$ for endotoxin-treated sheep. Cell viability was $>96 \%$, as determined by trypan blue exclusion.

\section{Chemiluminescence measurements}

Photon emission was measured over a period of 60 minutes in 3 ml-polystyrene vials, using a 6-channel Biolumat LB 9505 (Berthold, Wildbad, F. R. G.) and reagents prewarmed to $37^{\circ} \mathrm{C}$. Stimulation experiments with appropriate controls were performed according to table 1 . 
Tab. 1. Test compositions for chemiluminescence measurements

\begin{tabular}{|c|c|c|c|c|}
\hline & \multicolumn{2}{|c|}{ Tests with blood } & \multicolumn{2}{|c|}{$\begin{array}{l}\text { Tests with isolated neutrophils/ } \\
\text { alveolar macrophages }\end{array}$} \\
\hline & $\begin{array}{l}\text { Stimulation } \\
\text { (counts } / \mathrm{min}_{\mathrm{s}} \text { ) }\end{array}$ & $\begin{array}{l}\text { Control } \\
\text { (counts/min }{ }_{\mathrm{c}} \text { ) }\end{array}$ & $\begin{array}{l}\text { Stimulation } \\
\text { (counts } / \mathrm{min}_{\mathrm{s}} \text { ) }\end{array}$ & $\begin{array}{l}\text { Control } \\
\left.\text { (counts } / \min _{\mathrm{c}}\right)\end{array}$ \\
\hline Minimal essential medium & 500 & 520 & 500 & 520 \\
\hline Luminol $(22.6 \mathrm{mmol} / \mathrm{l})$ & 10 & 10 & 10 & 10 \\
\hline Zymosan A (100 g/l) & 20 & - & 20 & - \\
\hline Sheep plasma (pool) & - & - & 50 & 50 \\
\hline $\begin{array}{l}\text { Sample (blood and } 25000 \text { cells, } \\
\text { respectively) }\end{array}$ & 50 & 50 & 50 & 50 \\
\hline Total volume & 580 & 580 & 630 & 630 \\
\hline
\end{tabular}

Luminol (5-amino-2,3-dihydro-1,4-phthalazindione) was purchased from Boehringer-Mannheim, F. R. G., zymosan A from Sigma Chemical Co. St. Louis, MO, U. S. A.

The stimulatory response (counts/ $\mathrm{min}_{\mathrm{s}}-$ counts $/ \mathrm{min}_{\mathrm{c}}$ ) and the basic stimulation (counts $/ \min _{\mathrm{c}}$ ) values were calculated from the peak maximum values obtained (counts/min $\cdot 250000$ neutrophils for the experiments using whole blood and counts/min $\cdot 25000$ neutrophils/macrophages for the experiments using isolated cells).

The significance of differences between groups was calculated by the Wilcoxon matched pairs signed-ranks test and was accepted if $\mathrm{p}<0.05$.

\section{Results}

(i) Multiple bronchoalveolar lavage procedures by 'fixed position' balloon tipped catheter

On the day following the operative procedure, the second lavage aspirate already contained $65 \%$ neutrophils and this value increased up to more than $90 \%$ after 24 hours. This increase was dependent on the number of lavage procedures performed (fig. 1). In addition, endotoxin injection of $2 \mu \mathrm{g} / \mathrm{kg}$ of body weight 2 hours after the baseline lavage procedure $(0$ $\mathrm{min}$ ) resulted in a similar pattern of granulocyte infiltration (fig. 2). The average (range) total cell count was $0.41 \times 10^{9} / 1$ (range $\left.0.05-1.25 \times 10^{9} / 1\right)$ without endotoxin and $0.34 \times 10^{9} / 1$ (range $0.03-1.33$ $\left.\times 10^{9} / 1\right)$ with endotoxin. The total cell count for the baseline values was $0.041 \times 10^{9} / 1$ (range $0.022-0.063$ $\left.\times 10^{9} / 1\right)$.

(ii) Multiple bronchoscopies and multiple bronchoalveolar lavage procedures using long-term anaesthesia

One hour after endotoxin bolus injection of $2 \mu \mathrm{g} / \mathrm{kg}$ of body weight (4. lavage procedure) increasing proportions of granulocytes were observed in the s-segments, reaching a value of more than $80 \%$ after 8 hours (7. lavage procedure), whereas there was no

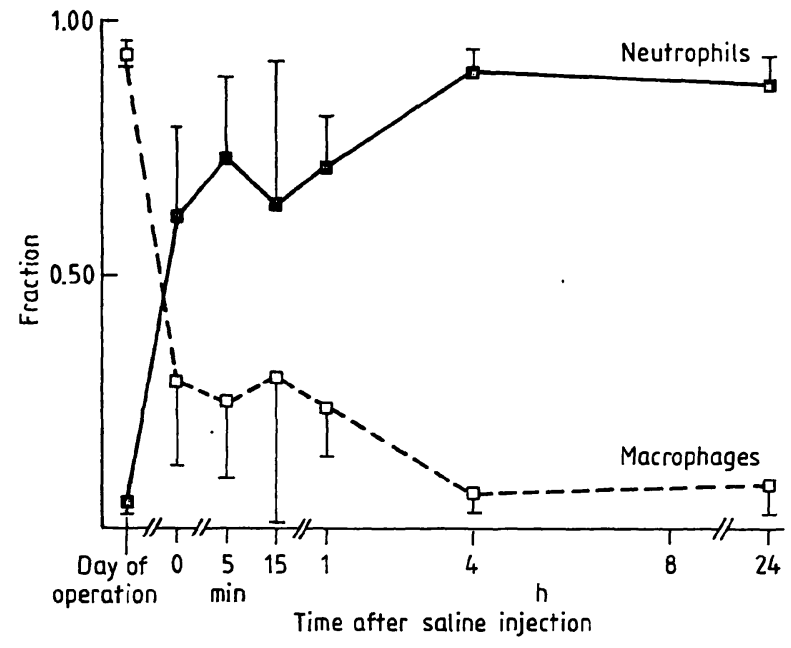

Fig. 1. Distribution of neutrophils (ㅁ) and alveolar macrophages $(\square)$ in lavage fluid of sheep which have undergone multiple bronchoalveolar lavage procedures by 'fixed position' balloon tipped catheter on the operation day (day before) and on the following day before $(0 \mathrm{~min})$ and after saline injection ( $5 \mathrm{~min}, 15 \mathrm{~min}, 1 \mathrm{~h}, 4 \mathrm{~h}, 24 \mathrm{~h}$ ) $\overline{\mathbf{x}} \pm \mathrm{SEM}, \mathrm{n}=3$

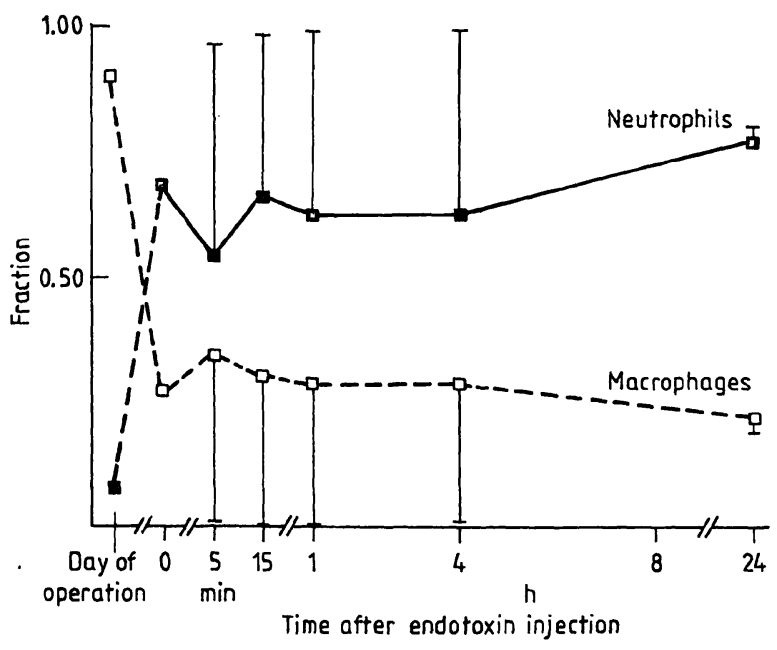

Fig. 2. Distribution of neutrophils ( $\square$ ) and alveolar macrophages $(\square)$ in lavage fluid of sheep which have undergone multiple bronchoalveolar lavage procedures by 'fixed position' balloon tipped catheter on the operation day (day before) and on the following day before ( $0 \mathrm{~min}$ ) and after ( $5 \mathrm{~min}, 15 \mathrm{~min}, 1 \mathrm{~h}, 4 \mathrm{~h}, 24 \mathrm{~h}$ ) endotoxin injection of $2 \mu \mathrm{g} / \mathrm{kg}$ of body weight

$\overline{\mathrm{x}} \pm \mathrm{SEM} ; \mathrm{n}=3$ 
corresponding increase in the proportion of granulocytes in the d-segments (fig. 3). The average (range) total cell count after endotoxin exposure was 0.011 $\times 10^{9} / 1$ (range $0.002-0.027 \times 10^{9} / 1$ ) for s-segments and $0.018 \times 10^{9} / 1$ (range $0.004-0.026 \times 10^{9} / 1$ ) for d-segments.

(iii) Multiple bronchoscopies and multiple bronchoalveolar lavage procedures using short-term anaesthesia

In these experiments the sheep were anaesthetized immediately prior to the lavage procedures. The proportion of granulocytes in s-segments was $15 \% 24$ hours (3. lavage procedure) after endotoxin bolus injection of $2 \mu \mathrm{g} / \mathrm{kg}$ of body weight, whereas no increase of the proportion of granulocytes was observed in the d-segments (fig. 4). The average (range) total cell count after endotoxin injection was $0.053 \times 10^{9} / 1$ (range $0.052-0.055 \times 10^{9} / 1$ ) for the s-segments and $0.044 \times 10^{9} / 1$ (range $0.04-0.049 \times 10^{9} / 1$ ) for the $d-$ segments. The baseline values obtained according to sections (ii) and (iii) showed an average cell pattern of $99 \%$ macrophages, $<1 \%$ neutrophils, $<1 \%$ lym-

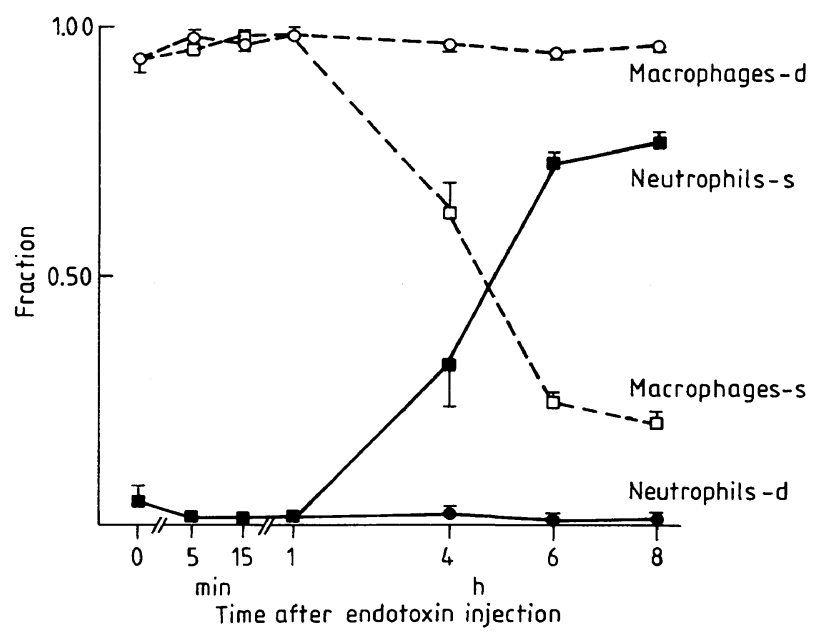

Fig. 3. Distribution of neutrophils and alveolar macrophages in lavage fluid of sheep which have undergone multiple bronchoscopies and multiple bronchoalveolar lavage procedures using long-term anaesthesia before $(0 \mathrm{~min})$ and after ( $5 \mathrm{~min}, 15 \mathrm{~min}, 1 \mathrm{~h}, 4 \mathrm{~h}, 6 \mathrm{~h}, 8 \mathrm{~h}$ ) endotoxin injection of $2 \mu \mathrm{g} / \mathrm{kg}$ of body weight

$\overline{\mathrm{x}} \pm \mathrm{SEM} ; \mathrm{n}=3$

$\mathrm{s}=$ same segment lavaged

$\mathrm{d}=$ different segments lavaged phocytes. The average (range) total cell count for the baseline values was $0.027 \times 10^{9} / 1$ (range $0.027-0.028$ $\left.\times 10^{9} / 1\right)$.

(iv) Chemiluminescence of alveolar macrophages and neutrophils from bronchoalveolar lavage fluid and of neutrophils from whole blood

The chemiluminescence behaviour of alveolar macrophages, obtained only from d-segments according to sections (ii) and (iii), was investigated. In addition, 7 analogous experiments using different lavage aspiration times after endotoxin exposure, were performed. One hour after endotoxin injection of $2 \mu \mathrm{g} /$ $\mathrm{kg}$ of body weight, the stimulatory response and the spontaneous photon emission showed an increase and a maximum after 4 hours (fig. 5a). Granulocytes, simultaneously isolated from venous blood samples, were in a hyperactive state upon zymosan A stimulation 5 minutes after endotoxin injection, and showed a minimal stimulatory response after 2 hours, followed by an increased response for up to 8 hours (fig. $5 b)$. Except for the phase of hyperactivity, the behaviour of the blood chemiluminescence response was identical (fig. 5c).

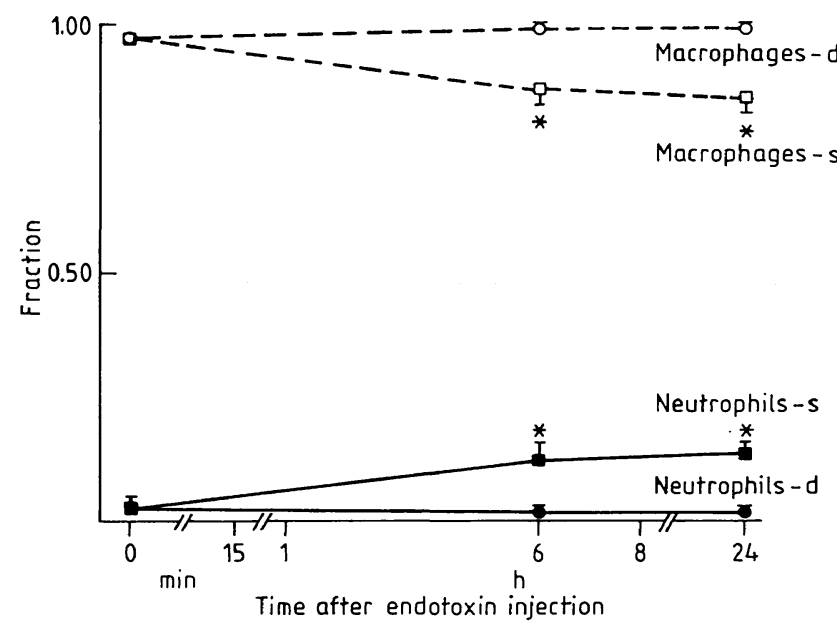

Fig. 4. Distribution of neutrophils and alveolar macrophages in lavage fluid of sheep which have undergone multiple bronchoscopies and multiple bronchoalveolar lavage procedures using short-term anaesthesia before $(0 \mathrm{~min})$ and after $(6 \mathrm{~h}, 24 \mathrm{~h})$ endotoxin injection of $2 \mu \mathrm{g} / \mathrm{kg}$ of body weight

$\overline{\mathrm{x}} \pm$ SEM; $\mathrm{n}=6$

$\mathrm{s}=$ same segment lavaged

$\mathrm{d}=$ different segments lavaged

* $\mathrm{p}<0.056 \mathrm{~h}$ and $24 \mathrm{~h}$ values vs 0 min values 


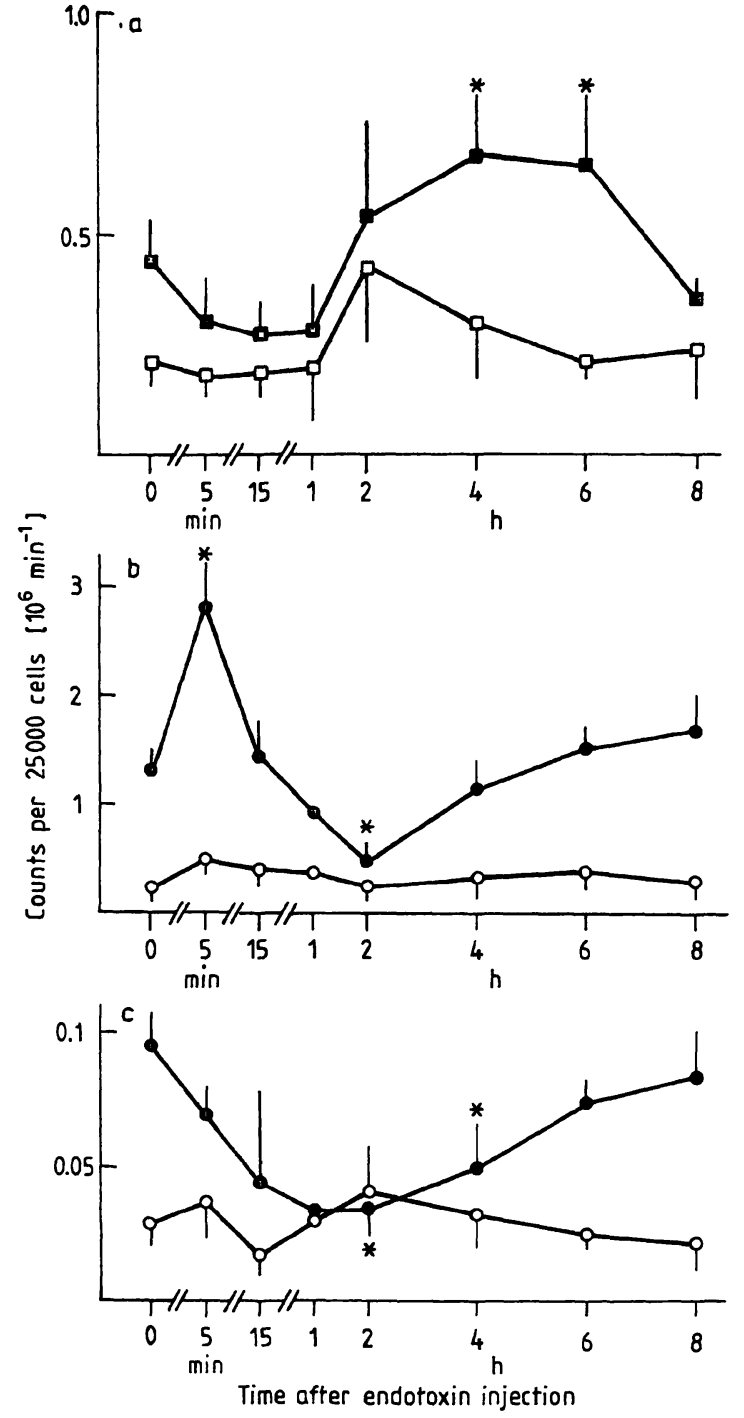

Fig. 5. Chemiluminescence responses of alveolar macrophages (a) neutrophils isolated from blood (b) and citrated blood (c) of sheep before ( $0 \mathrm{~min})$ and after $(5,15 \mathrm{~min} ; 1,2,4,6$, $8 \mathrm{~h}$ ) endotoxin injection of $2 \mu \mathrm{g} / \mathrm{kg}$ of body weight with (filled symbols) and without (open symbols) zymosan A stimulation

$\overline{\mathrm{x}} \pm \mathrm{SEM} ; \mathrm{n}=16$

* $\mathrm{p}<0.054 \mathrm{~h}$ and $6 \mathrm{~h}$ values vs 0 min values (a)

* $\mathrm{p}<0.055 \mathrm{~min}$ and $2 \mathrm{~h}$ values vs 0 min values (b)

* p $<0.055 \mathrm{~min}, 2 \mathrm{~h}, 4 \mathrm{~h}$ and $6 \mathrm{~h}$ values vs $0 \mathrm{~min}$ values (c)

\section{Discussion}

Stimulated polymorphonuclear neutrophilic leukocytes are believed to be the cells which initiate and/ or amplify the development of the adult respiratory distress syndrome $(14,15,17,18)$. Furthermore, to investigate pathomechanisms of this disease, the endotoxin-induced permeability increase in sheep is widely used as an acute model for the adult respiratory distress syndrome. Therefore, biochemical parameters that are indicative of the permeability increase should correlate with functional and/or topographical alterations of granulocytes in this animal model $(3-5)$.

From our results it was demonstrated that mechanical irritation by the 'fixed position' balloon catheter induced a heavy invasion of granulocytes into the alveoli, even without endotoxin exposure. Also, the slight irritation and inflammatory reaction produced by the bronchoscopy and a single bronchoalveolar lavage procedure can initiate the granulocyte invasion, especially in the case of repeated lavage procedures of the same bronchial segment, as described by Weiss et al. (23). In contrast, only the d-segments contained normal granulocyte/alveolar macrophage ratio in the lavage fluid after endotoxin injection for up to seven lavage procedures of the same animal within an 8 hour period. It can be concluded, therefore, that there was no increase in granulocyte migration into the alveoli within the period of increased permeability between 2 and 6 hours after endotoxin injection, despite their increased adherence in the lung capillaries $(1,2)$. Therefore, the initiation and/or amplification of the permeability damage, presumably caused by granulocytes, seemed to be restricted to the capillary endothelium.

From the stimulatory responses of blood neutrophils and alveolar macrophages and their time courses, the early ( $5 \mathrm{~min}$ ) hyperactivation by endotoxin of blood neutrophils was demonstrated, as well as their consecutive metabolic exhaustion with a minimal chemiluminescence response after 2 hours. The ensuing increase was presumably caused by new granulocytes liberated by the bone marrow. In contrast, alveolar macrophages exhibited an increase in their stimulatory response and spontaneous photon emission, beginning 1 hour after endotoxin injection and peaking after 4 hours. The observed time course was nearly identical with the permeability increase and its decrease after endotoxin injection $(3,4)$. From the time courses of activation of blood granulocytes and alveolar macrophages it is possible to cautiously propose a pathogenetic sequence. Early intravascular stimulation/activation of neutrophils can cause an increase of their adherence to the capillary endothelium, followed by secretion of mediators, which after some delay, can diffuse into the alveoli and stimulate alveolar macrophages, without the granulocytes leaving the capillary and entering the alveolar space.

\section{Acknowledgement}

This work was supported by the 'Deutsche Forschungsgemeinschaft', project II B6. 


\section{References}

1. Regel, G., Nerlich, M. L., Dwenger, A., Seidel, J., Schmidt, C. \& Sturm, J. A. (1987) Phagocytic function of polymorphonuclear leukocytes and the RES in endotoxemia. J. Surg. Res. 42, 74-84.

2. Snapper, J. R., Bernard, G. R., Hinson Jr., J. M., Hutchison, A. A., Loyd, J. E., Ogletree, M. L. \& Brigham, K. L. (1983) Endotoxemia induced leukopenia in sheep: correlation with lung vascular permeability and hypoxemia but not with pulmonary hypertension. Am. Rev. Respir. Dis. 127, 306-309.

3. Brigham, K. L. \& Meyrick, B. (1986) Endotoxin and lung injury. Am. Rev. Respir. Dis. 133, 913-927.

4. Brigham, K. L., Bowers, R. E. \& McKeen, C. R. (1981) Methylprednisolone prevention of increased lung vascular permeability following endotoxemia in sheep. J. Clin. Invest. $67,1103-1110$.

5. Staub, N., Bland, R., Brigham, K., Demling, R., Erdmann, J. \& Woolverton, W. (1975) Preparation of chronic lung lymph fistulas in sheep. J. Surg. Res. 19, 315-320.

6. Begley, C. J., Ogletree, M. L., Meyrick, B. O. \& Brigham, K. L. (1984) Modification of pulmonary responses to endotoxemia in awake sheep by steroidal and nonsteroidal anti-inflammatory agents. Am. Rev. Respir. Dis. 130, $1140-1146$

7. Bernard, G. R. \& Brigham, K. L. (1985) The adult respiratory distress syndrome. Ann. Rev. Med. 36, 195-205.

8. Brigham, K. L. (1986) Role of free radicals in lung injury. Chest 89, 859-863.

9. Dobrina, A. \& Patriarca, P. (1986) Neutrophil-endothelial cell interaction. Evidence for and mechanisms of the selfprotection of bovine microvascular endothelial cells from hydrogen peroxide-induced oxidative stress. J. Clin. Invest. $78,462-471$.

10. Dwenger, A., Regel, G., Neumann, C. \& Schweitzer, G. (1986) Pathomechanisms of the adult respiratory distress syndrome (ARDS): elastase contents of polymorphonuclear leukocytes and elastase release during passage across the blood/air barrier. Fresenius Z. Anal. Chem. 324, 359-360.

11. Dwenger, A., Schweitzer, G., Regel, G. \& Neumann, C. (1987) Chemiluminescence response of human polymorphonuclear leukocytes before and after passage of the blood/air barrier. In: Bioluminescence and chemiluminescence, new perspectives; Proceedings of the IV international bioluminescence and chemiluminescence symposium (Schölmerich, J., Andreesen, R., Kapp, A., Ernst, M. \& Wood, W. G., eds.) pp. $41-44$, John Wiley \& Sons, Chichester, New York, Brisbane, Toronto, Singapore.
12. Harlan, J. M. (1985) Leukocyte-endothelial interactions. Blood 65, 513-525.

13. Jonas, E., Dwenger, A. \& Lueken, B. (1988) Chemiluminescence response and endothelial cell damage following lipopolysaccharide priming of polymorphonuclear leukocytes. Fresenius Z. Anal. Chem. 330, 421-422.

14. Regel, G., Dwenger, A., Seidel, J., Nerlich, M. L., Sturm, J. A. \& Tscherne, H. (1987) Die Bedeutung der neutrophilen Granulozyten bei der Entstehung des posttraumatischen Lungenversagens. Unfallchirurg 90, 99-106.

15. Rinaldo, J. E. (1986) Mediation of ARDS by leukocytes. Clinical evidence and implications for therapy. Chest 89 , $590-593$.

16. Ryan, U. S. \& Ryan, J. W. (1984) Cell biology of pulmonary endothelium. Circulation 70 (suppl III), 46-62.

17. Tate, R. M. \& Repine, J. E. (1983) Neutrophils and the adult respiratory distress syndrome. Am. Rev. Respir. Dis. $128,552-559$.

18. Worthen, G. S. \& Henson, P. M. (1983) Mechanisms of acute lung injury. Clin. Lab. Med. 3, 601-617.

19. Worthen, G. S., Haslett, C., Smedly, L. A., Rees, A. J., Gumbay, R. S., Henson, J. E. \& Henson, P. M. (1986) Lung vascular injury induced by chemotactic factors: enhancement by bacterial endotoxins. Fed. Prod. 45, 7-12.

20. Nerlich, M. L., Wisner, D. H., Albes, J. \& Sturm, J. A. (1985) Pulmonary effects of iv injection of bone marrow fat and endotoxemia in sheep. Langenbecks Arch. Chir. Suppl. 1985, 55-58.

21. Mc Guire, W. W., Spragg, R. G., Cohen, A. B. \& Cochrane, C. G. (1982) Studies on the pathogenesis of the Adult Respiratory Distress Syndrome. J. Clin. Invest. 69, 543553.

22. Tucker, S. B., Pierre, R. V. \& Jordan, R. E. (1977) Rapid identification of monocytes in a mixed mononuclear cell preparation. J. Immunol. Meth. 14, 267-269.

23. Weiss, R. A., Chanana, A. D. \& Joel, D. D. (1983) Localized pulmonary neutrophil influx induced by lung lavage in sheep. Lung $161,369-374$.

Dr. rer. nat. Alexander Dwenger Abteilung für Klinische Biochemie Medizinische Hochschule Hannover Konstanty-Gutschow-Straße 8 D-3000 Hannover 61 